\title{
Dynamic Traffic Light Control for Intelligent Mobility of Emergency Vehicles
}

\author{
N.S. Sahana, Krupa S. Bhat, M. Aishwarya, Lalitha Kanumilli and J. Mumtaz Bhanu
}

\begin{abstract}
Traffic congestion is a major problem in cities of developing countries. Emergency vehicles need to reach their destination at the earliest. If a lot of time is spent in traffic jam, valued lives of many people may be in danger. In this system, the image sequences from a camera are analyzed using various edge detection and object counting methods to obtain the most efficient technique. Then, the number of vehicles at the intersection is evaluated and traffic is efficiently managed. The traffic signal indication continuously glows to green as long as the emergency vehicle is waiting at the traffic lane. After the vehicle crosses the junction, automatically the traffic signals follow the previous pattern generation of traffic signals.
\end{abstract}

Keywords--- Arduino, Raspberry PI, Global Positioning System(GPS), Image Processing, WiFi Module, Ethernet Shield, Regular Next Signal(RNS) Algorithm, Emergency Vehicle Traffic Preemption(EVTP) Algorithm.

\section{INTRODUCTION}

$\mathrm{T}$ HE fixed time traffic light control systems rely on an electro-mechanical signal controller and dial timers to keep a specific color for a given period of time. Dynamic traffic light control system is a simple device that communicates with the traffic light and informs it about traffic conditions in real time. Thus, the traffic light can not only adjust timing, but also solve traffic jams by turning its color as soon as an intersection gets stuck with cars. One of the most critical consequences of traffic problem is the delay of emergency vehicles. . This imposes considerable delay in response time[1]. Conventionally, commuters give way to emergency vehicles, on hearing the vehicle's siren. But an emergency vehicle passing an intersection poses danger to traffic approaching the signal from other roads. Thus an emergency vehicle has to wait for the entire traffic signal cycle to complete in order to pass the intersection. The other problem is though the emergency vehicles can override the traffic signals, sometimes it may not be able to do so as there

N.S. Sahana, Student, Department of CSE, SDM College of Engineering and Technology,Dharwad, India.E-mail:nssahana13@gmail.com

Krupa S. Bhat, Student, Department of CSE, SDM College of Engineering and Technology, Dharwad, India.E-mail:krupabhat24@gmail.com

M. Aishwarya, Student, Department of CSE, SDM College of Engineering and Technology, Dharwad, India, Department, Organization/University, City, Country.E-mail:aishwaya14m@gmail.com

Lalitha Kanumili, Student, Department of CSE, SDM College of Engineering and Technology, Dharwad, India. E-mail:lalithak888@gmail.com

J. Mumtaz Bhanu Student, Department of CSE, SDM College of Engineering and Technology, Dharwad, India.E-mail:munnyj6@gmail.com DOI:10.9756/BIJSESC.8268 may be traffic jam or vehicles waiting for the signal to change ahead of it. Besides, the collisions with other vehicles from other direction might occur at intersections when emergency vehicles override the red traffic lights. All these difficulties faced by emergency vehicles can be avoided using this dynamic traffic light control system.

\section{LITERATURE SURVEY}

Nikhil Mascarenhas1, Pradeep G1, Manish Agrawal1, Subash P1, Ajina A "A PROPOSED MODEL FOR TRAFFIC SIGNAL

\section{PREEMPTION USING GLOBAL POSITIONING SYSTEM (GPS)" [2]}

The proposed model will use GPS hardware, already existing in most smart phones, to receive and transmit GPS signals. These signals are transmitted to a central server which can communicate to traffic signal controllers via Internet. An Arduino Microcontroller at each traffic intersection with an Ethernet Shield to enable it to connect to the Internet. An Android Application for an Android Smartphone will have to be carried by the staff of each ambulance. This app will receive GPS coordinates and transmit the same to a web server. A Web Server which receives GPS coordinates of all emergency vehicles and then sends preemption signals to traffic signal controllers accordingly. The only demerit of the proposed system is that in densely populated cities, tall buildings may prevent satellite signals in reaching the GPS receiver. This demerit doesn't pose much threat as Android smart phones are capable of computing location based on mobile tower triangulation and also close range Wi-Fi signals. Only precaution that needs to be taken is security of the smart phone.

Ashwini Basavaraju, Senhalata Doddigarla, Navitha Naidu, Shruti Malgatti "VEHICLE DENSITY SENSOR SYSTEM TO MANAGE TRAFFIC"[3]

In this study, we adapt the approach to take data/input/image from object/ subject/vehicle and to process the input data by Computer and Microcontroller and finally display it on the traffic light signal to control the Closed Loop System. The system is based on microcontroller. The system contains IR transmitters and IR receivers which are mounted on the either sides of roads. This IR system gets activated when any vehicle passes on road between IR transmitter and IR receiver. The microcontroller controls the IR system and counts number of vehicles passing on road at that particular time. The microcontroller also store vehicles count in its memory. Based on different densities of vehicles, the microcontroller decides the wait time and updates the traffic light delays. By this process the administrator on a central 
station computer can access traffic conditions on any connected traffic light and nearby roads to reduce traffic congestions to an extent. The disadvantages that need to be overcome are: detection artifacts caused by shadows, reflections from the roadway and or varying weather conditions.

\section{PROPOSED SYSTEM}

Now days, there is high traffic at a particular time due to which the traffic signals should be maintained correctly to reduce accidents but at the same time, during some emergency situations ambulance may be blocked in the signal which may

leads to major casualty. To avoid this, based on statistics, traffic signal should be controlled. IoT plays the role between ambulance and the traffic signals[9]. Cloud computing provides the way for handling and managing the enormous amount of data that are generated by these devices. Extensive research work had been carried in the field of object based system ranging from GSM based location determination [4] to GPS based location determination [5][6].

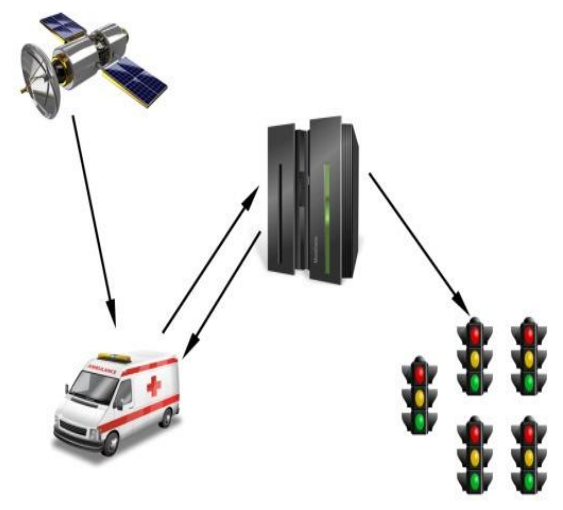

Figure 1: [2]

The proposed system consists of following components as depicted in Fig.1.

1) An Arduino Microcontroller at each traffic intersection with a $\mathrm{WiFi}$ module to enable it to connect to the Internet and with GPS module to send the location of ambulance to the cloud.

2) An Android Application for an Android Smartphone will have to be carried by the staff of each ambulance. This app will receive START location and STOP location and transmit the same to the cloud for further processing.

3) Raspberry pi with camera at each junction captures the congestion by counting the number of vehicles at the traffic junction.

4) Cloud which receives the GPS coordinates of all emergency vehicles and the congestion at the traffic junction takes decision according to the algorithm proposed.

5) Announcement can be made about the approaching ambulance, so that the commuters vacate a lane.[11]
Table 1: Comparison Of Technologies[2]

\begin{tabular}{|l|l|l|l|l|}
\hline \multicolumn{1}{|c|}{ Consideration } & $\begin{array}{c}\text { Acoustic } \\
\text { System } \\
\text { System }\end{array}$ & $\begin{array}{l}\text { Line of } \\
\text { Sight }\end{array}$ & $\begin{array}{c}\text { Radio } \\
\text { System }\end{array}$ & $\begin{array}{c}\text { Proposed } \\
\text { Model } \\
(\text { GPS })\end{array}$ \\
\hline $\begin{array}{l}\text { Dedicate Emitter } \\
\text { Required? }\end{array}$ & No & Yes & Yes & Yes \\
\hline $\begin{array}{l}\text { Susceptible to } \\
\text { Electronic Noise } \\
\text { Interference? }\end{array}$ & No & No & Yes & No \\
\hline $\begin{array}{l}\text { Clear Line of Sight } \\
\text { Required? }\end{array}$ & Yes & No & No & No \\
\hline Affected by weather? & No & Yes & No & No \\
\hline $\begin{array}{l}\text { Possible Preemption } \\
\text { of Other Approaches }\end{array}$ & Yes & No & Yes & No \\
\hline $\begin{array}{l}\text { Possibility of Illegal } \\
\text { Triggering of } \\
\text { Preemption }\end{array}$ & High & High & High & Low \\
\hline $\begin{array}{l}\text { Centralized Traffic } \\
\text { Signal Monitoring } \\
\text { and Log Statistics }\end{array}$ & No & No & No & Yes \\
\hline
\end{tabular}

\section{METHODOLOGY}

For Emergency vehicle detection and traffic clearance Emergency Vehicle Traffic Pre-emption (EVTP) Algorithm is used:

1) Declare latitude and longitude of GPS as zero initially.

2) Allocate the static value of the traffic signal which is the distance before $1 \mathrm{~km}$ of the signal[14].

3) The driver of emergency vehicle is required to set his start location and target location through the application made available.

4) The GPS module will continuously track the emergency vehicle and update the latitude and longitude values[13].

5) Compare both static value and updated values.

6) If both values are same then cloud automatically changes the signal to green[15].

7) After the vehicle crosses the signal, the updated value is compared with static value of next approaching signal and this process repeats until the ambulance reaches its final destination.

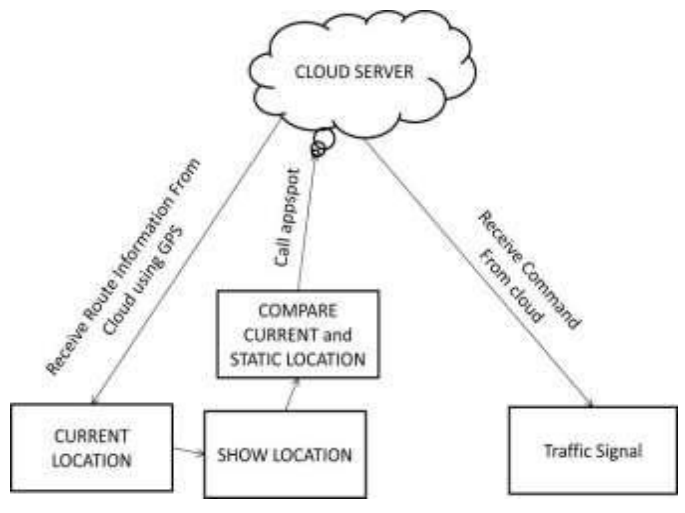

Figure 2: [6] 
For dynamic control of traffic signal when Emergency vehicle is not detected, we use RNS (Regular Next Signal)

Algorithm

1) Activate the system with the power supply.

2) Measure the traffic density of all the junction by activating all the ultrasonic sensors $\left(\mathrm{s}_{\mathrm{n}}, \mathrm{s}_{\mathrm{n}+1}, \mathrm{~s}_{\mathrm{n}+2}, \mathrm{~s}_{\mathrm{n}+3}\right)$ of all four roads simultaneously. Here $\mathrm{n}$ represents all street, let $n=1$.

3) Send these pulses to raspberry pi that takes decision of level of jam on that road.[8]

a) Let $d_{n}, d_{n+1}, d_{n+2}, d_{n+3}$ be the traffic density of all four roads.

b) If $d_{n}>d_{n+1}$ is false that is traffic density of first road is less than the density of second road then check the condition $d_{n+1}>d_{n+2}$ and if false then it will check $d_{n+2}>d_{n+3}$ and if false then check $d_{n+2}>d_{n+3}$. Thus the road that is highly dense in respect to road density of first road is found out.

c) If, $d_{n}>d_{n+1}$ is true than check the condition $d_{n}>d_{n+2}$ and if false, then check the condition $d_{n+2}>d_{n+3}$. Thus, road is highly dense in respect to road density of first and second road is found.

d) If condition $d_{n}>d_{n+21}$ is true then check the condition $d_{n}>d_{n+3}$, all these conditions after processing gives us the highly denser road among the four road.

1) Now the densest road is known, make that road as reference road and raspberry pi makes the output to the all the traffic lights on the poles as $g_{n}, r_{r n+1}, r_{r n+2}$, $\mathrm{r}_{\mathrm{rn}+3}$ where $\mathrm{g}$ denotes green light for the road which is highly dense and $\mathrm{r}$ denotes red light for remaining three roads.

2) Raspberry pi always checks the time period of green light, the allotted time period for green light remains only $40 \sec [12]$ then raspberry pi activates the sensors and go back to step 2 .

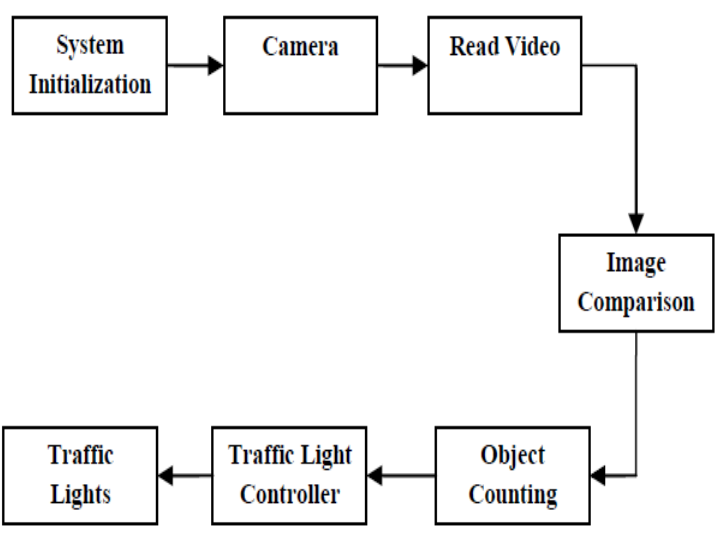

Figure 3:[7]

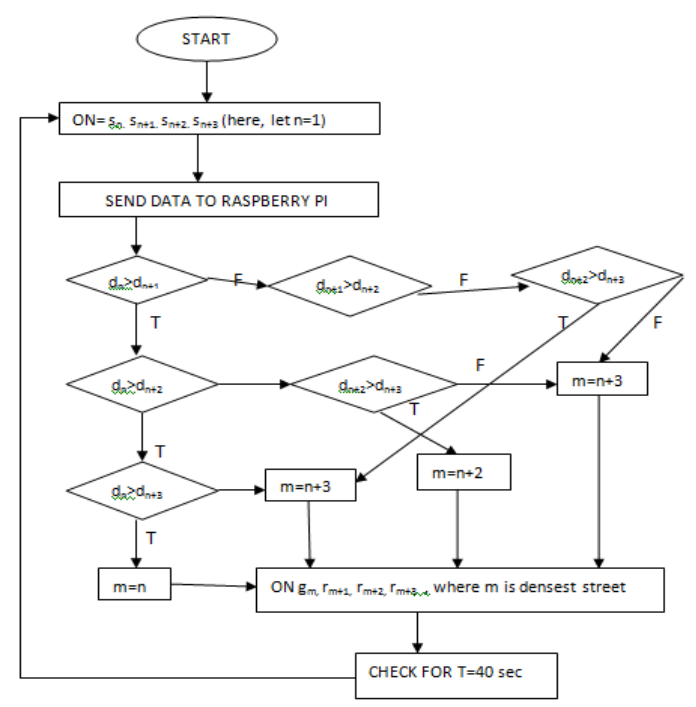

Figure 4: Application and Future Scope

The Arduino microcontroller and raspberry pi once installed can be used for various other purposes:

1) Smart Traffic Management: Using traffic data obtained from various sources such as Google Traffic and Traffic updates from ground controllers, the same server-centric model, using the same microcontroller can be used to slightly manipulate and vary traffic signal timings to ease congested roads.

2) The same microcontroller, Raspberry pi can also be used to display traffic updates on LED screens at traffic signals, so commuters can avoid congested routes.

3) Speed detecting sensors and other sensors can also be connected to Raspberry pi and violations can be viewed automatically at the Central office.

4) Since the Arduino microcontroller can be used with different types of hardware, this server-centric model using Arduino and GPS can also be used for similar applications such as:

1. Automated closing and opening of railway gates.

2. Dynamic display of bus arrivals and bus timings at bus stops for passenger convenience.

3. Anti-collision systems in railways.

1. The ambulance driver may get suggestions to avoid congested roads and prefer other less congested roads.

2. Smart mobility is one of the eight key factors that define a smart city according to Frost \& Sullivan, together with the other seven aspects shape the cities of the future.[10]

\section{CONCLUSION}

By using this system configuration we try to reduce the possibilities of traffic jams, caused by traffic lights. Number of passing vehicle on the road decide the density range of traffic and on the basis of vehicle count Raspberry PI decide the traffic light delays for next recording interval. This model also presents a solution for the easy passage of emergency vehicles by means of preemption of signals at intersections. Traffic signal preemption if implemented can reduce emergency 
response time and increase road safety with minimum inconvenience to regular traffic.

\section{REFERENCES}

[1] V. Venkatesh and N. Syed, "Smart Traffic Control System for Emergency Vehicle Clearance", International Journal of Innovative Research in Computer and Communication Engineering, Vol. 3, No. 8, 2015.

[2] N. Mascarenhas, G. Pradeep, M. Agrawal, P. Subash and A. Ajina "A Proposed Model for Traffic Signal Preemption Using Global Positioning System (GPS)", 2013.

[3] A. Basavaraju, S. Doddigarla, N. Naidu and S. Malgatti, "Vehicle Density Sensor System to Manage Traffic", IJRET, 2014.

[4] S. Wang, J. Min and B.K. Yi, "Location based services for mobiles: Technologies and standards", In international conference on IEEE communication, Pp. 35-38, 2008.

[5] T.M. Brown, S.A. McCabe and C.F. Wellford, "Global positioning system (GPS) technology for community supervision: Lessons learned", Noblis. No. 219376, 2007.

[6] Dr.A. Balamurugan, G. Navin Siva Kumar, S. Raj Thilak and P. Selvakumar, "Automated Emergency System in Ambulance to Control Traffic Signals using IoT", International Journal Of Engineering And Computer Science, Vol. 4, No. 4, 2015.

[7] V. Venkatesh and N. Syed "Smart Traffic Control System for Emergency Vehicle Clearance", International Journal of Innovative Research in Computer and Communication Engineering, No. 8, 2015.

[8] A. Jain, M. Mittal, H. Verma and A. Rai, "Traffic Density Measurement based On-road Traffic Control using Ultrasonic Sensors and GSM Technology", Association of Computer Electronics and Electrical Engineers, (ACEE), 2013.

[9] K. Sangeetha, P. Archana , M. Ramya and P. Ramya, "Automatic Ambulance Rescue With Intelligent Traffic Light System", IOSR Journal of Engineering (IOSRJEN), Vol. 04, No. 02, 2014.

[10] B.A. Mohamed, A. Ghadi, A. Boudhir, M. bouhorma and B.A. Kaoutar, "Dynamic traffic light control FOR intelligent Mobility in Smart Cities", Journal of Theoretical and Applied Information Technology, Vol. 73, No. 2, 2015.

[11] N.M.Z. Hashim, A.S. Jaafar, N.A. Ali, L. Salahuddin, N.R. Mohamad and M.A. Ibrahim, "Traffic Light Control System for Emergency Vehicles Using Radio Frequency", IOSR Journal of Engineering (IOSRJEN), Vol. 3, No. 7, 2013.

[12] H.R. Al -Zoubi, B.A. Mohammad, S.Z. Shatnawi and A.I. Kalaf, "A simple and efficient traffic light preemption by emergency vehicles using cellular phone wireless control", In Proceedings of the 13th WSEAS international conference on Mathematical and computational methods in science and engineering, Pp. 167-170, 2011.

[13] P. Kalegore, D. Nair, A. Pillai and M. Wanjre, "Real Time Vehicle Tracking on Google Earth Using Wireless Technology", International Journal of Advance Engineering and Research, Vol.3, No. 3, 2016.

[14] R. Hegde, R.R. Sali and M.S. Indira, "RFID and GPS Based Automatic Lane Clearance System for Ambulance", International Journal of Advanced Electrical and Electronics Engineering (IJAEEE), Vol. 2, No. 3, 2013.

[15] K.M. Yousef, M.N. Al-Karaki and A.M. Shatnawi, "Intelligent Traffic Light Flow Control System Using Wireless Sensors Networks", Vol. 26, No. 3, Pp. 753-768, 2010.

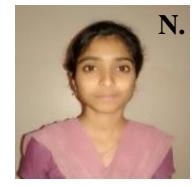

S. SAHANA, currently pursuing final year B.E. in SDM College of Engineering and Technology, Dharwad, Karnataka.

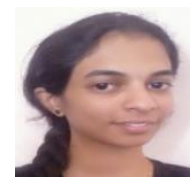

KRUPA S. BHAT, currently pursuing final year B.E. in SDM College of Engineering and Technology, Dharwad, Karnataka.

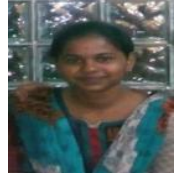

M. AISHWARYA, currently pursuing final year B.E. in SDM College of Engineering and Technology

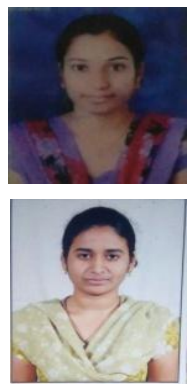

LALITHA

KANUMILLI,

currently pursuing final year B.E. in SDM College of Engineering and Technology, Dharwad, Karnataka.

J. MUMTAZ BHANU, currently pursuing final year B.E. in SDM College of Engineering and Technology, Dharwad, Karnataka. 